\title{
PEMANFAATAN Tyto alba SEBAGAI PENGENDALI HAMA TIKUS DI PERKEBUNAN KELAPA SAWIT DI KABUPATEN KUANTAN SINGINGI
}

\author{
SEPRIDO $^{1 *}$ DAN MASHADI ${ }^{2}$ \\ 1,2. Program Studi Agroteknologi, Fakultas Pertanian Universitas Islam Kuantan \\ Singingi \\ Jl. Gatoto Subroto KM 7 Kebun Nenas Jake Teluk Kuantan (29562) \\ *E-mail: sepridhopiliang@ymail.com
}

\begin{abstract}
ABSTRAK
Penelitian tentang pemanfaatan Tyto alba sebagai pengendali hama tikus di perkebunan kelapa sawit kabupaten Kuantan Singingi ini dilakukan pada bulan April-November 2018 di beberapa perkebunan kelapa sawit di Kabupaten Kuantan Singingi. Metode yang digunakan dalam penelitian ini adalah survey yang dilakukan di dasarkan pada Barn Owl Survey Protocol, penghitungan populasi Tyto alba dilakukan secara langsung di lapangan, penghitungan jumlah mangsa dengan melakukan pemasangan camera trap pada kandang butan Tyto alba di areal perkebunan. Dari hasil penelitian yang dilakukan diketahui bahwa di kabupaten Kuantan Singingi Tyto alba masih digunakan sebatas pada Perkebunan besar swasta, Salah satunya adalah PT. Tri Bakti Sarimas (PT. TBS). Pada perkebunan kelapa sawit PT. TBS ini telah menggunakan Tyto alba sebagai pengendali hama tikus secara keseluruhan dengan membuat 3000 nestbox sejak tahun 2012 yang tersebar satu kandang untuk 25 ha pada perkebunan inti. Sekitar $85 \%$ diantaranya telah didiami oleh Tyto alba dengan bukti dijumpainya pada rumah burung hantu yang dibangun dijumpai adanya telur, anakan dan cangkang telurnya.
\end{abstract}

Kata Kunci : Tyto alba, Kelapa sawit, Kuantan Singingi, Tikus, Hama

\section{ABSTRACT}

Research about the utilization of Tyto alba as rats pest control in oil palm plantations Regency of Kuantan Singingi was done in April-November 2018 in some palm oil plantations in the district of Kuantan Singingi. The methode of this research followto The Barn Owl Protocol, Calculation of the population Tyto alba was directly in area of plantations, counting the number of the prey doing by installation of Camera Trap in artificial enclosure and types of the prey was analysis by skull of the prey in on pellets of Tyto alba. Results of this research show in Kuantan Singingi Regency, The utilization of Tyto alba is still used internally by large private oil palm Plantation, one of Them is PT. Tribakti Sarimas (PT. TBS). On PT. TBS'S oil palm plantations has been using as whole by making a artificial enclosure (Nestbox) 3.000 Unit since 2012 year which spread a cage of for 25 ha on the estate's core. About 85\% of whom had been inhabited by Tyto alba with the evidence she had met the presence of eggs, chicks and eggs have shells.

Keywords: Tyto alba, Oil palam, Kuantan Singingi, Rats, Pest

Diterima : 4 Januari 2019, disetujiui : 22 Maret 2019 


\section{PENDAHULUAN}

Sumatera merupakan pulau di Indonesia yang memiliki luasan perkebunan kelapa sawit terluas di Indonesia, pada tahun 2015 yakni 7.032.857 ha dengan total produksi 21.442.711 ton. Dan diikuti oleh Kalimantan dengan luasan 4.178.992 ha serta produksi 9.447.576 ton. Di sumatera, Riau merupakan provinsi yang memiliki luasan peerkebunan kelapa sawit terluas di Indonesia pada tahun 2015 yakni seluas 2.4 juta hektar dengan total produksi 8.059 ton. Kemudian diikuti oleh Sumatera utara (1.4 juta dengan produksi 5.193.135 ton) dan Sumatera selatan (952.082 ha dengan produksi 2.821.938 ton (Annonymous, 2016). Di kabupaten Kuantan Singingi, perkebunan kelapa sawit merupakan salah satu agroekosistem yang diupayakan dlaam jumlah besar, terdapat dua upaya pengembangan perkebunan yakni skala petani dan perusahaan besar swasta (Seprido, 2018).

Luasnya perkebunan kelapa sawit ini pastinya juga menghadapi banyaknya tantangan, sama halnya dengan padi yang mempengaruhi adanya tikus sebagai hama (Daniel Harjanto, Ignatius Pramana Yuda, 2009), pada perkebunan kelapa sawit juga juga bisa mempengaruhi produksinya oleh tikus (Motro, 2011). Tikus merupakan hama utama dalam perkebunan kelapa sawit, baik pada tanaman yang baru ditanam, tanaman belum menghasilkan bahkan juga pada tanaman menghasilkan. Kerugian yang disebabkan tikus ini dapat mencapai 5\% dari total $\mathrm{CPO} / \mathrm{ha} / \mathrm{th}$ pada tanaman yang menghasilkan dan dapat mencapai $80 \%$ pada tanaman muda (Dhamayanti, 2009). Ditambahkan oleh Motro (2011) bahwa kehadiran Tyto alba sangat membrikan pengaruh positif terhadap pertanian alfala serta menjaga kesehatan lingkungan.

Tikus dianggap sebagai hama (Singh, Minerva and Bhagwat, 2013). Seekor tikus mampu memakan bonggol tanaman kelapa sawit pada TBM serta memakan bunga atau buah pada TM. Sehingga dapat menurunkan kualitas CPO. Selain itu, kemampuan seekor tikus dalam mengkonsumsi buah kelapa sawit adalah 6-4 gr/hari atau setara dengan $328-962 \mathrm{Kg} / \mathrm{ha} / \mathrm{th}$, dengan tingkat populasi tikus perhektar berkisar antara 183-537 ekor (Dhamayanti, 2009).

Hama tikus dapat dikendalikan secara kimia dan biologi.. Dengan metode kampanye menggunakan racun tikus yang dipasang didekat setiap pohon kelapa sawit dan dilakukan dua kali dalam setahun (Rajagukguk, 2014). Secara umum pengendalian populasi tikus dengan menggunakan bahan kimia juga dapat mengganggu kondisi lingkungan dan akumulasi dalam tubuh Tyto alba (Newton, Wyllie, \& Freestone, 1990).

Hama tikus dapat dikendalikan dengan menggunakan predator sebagai musuh alaminya, salah satunya adalah Tyto alba (Huffeldt et al., 2012). Penggunaan burung hantu jenis ini relatif lebih aman jika dibandingkan dengan penggunaan ular yang bisa membahayakan keselamatan tenaga kerja.

Tyto alba merupakan predator yang sangat potensial untuk mengendalikan tikus secara biologi di perkebunan kelapa sawit seekor Tyto alba dapat memangsa 2-5 ekor tikus setiap harinya. (Rajagukguk, 2014). Sebelumnya, Sipayung dkk (1990) menyatakan juga bahwa seekor Tyto alba dapat memangsa 3000 ekor tikus pertahun selain itu juga memiliki kemampuan berkembang biak yang sangat cepat dan daya jelajah dapat mencapai 3-1 km.

Populasi Tyto alba yang menurun penyebabnya antara lain adalah adanya perubahna iklim, gangguan manusia, kehilangan tempat berburu, dan penggunaan pestisida (Singh, Minerva and Bhagwat, 2013). Penggunaan rodentisida dapat meracuni telur Tyto alba secara sekunder 
pada albumen dan yolk telurnya (Salim et al., 2015)(Shakir, Osborne-lee, Paolo, Misso,

\section{METODE PENELITIAN}

Penelitian ini merupakan penelitian survey yang dilaksanakan pada bulan AprilNovember 2018 di Perkebunan kelapa sawit PT. Tri Bakti Sarimas Kabupaten Kuantan Singingi dan di lanjutkan di Laboraturium Fakultas Pertanian Universitas Islam Kuantan Singingi.

Survey dalam penelitian ini mengacu kepada Barn Owl Survey Metodology menurut (Shawyer, 2011). Survey ini terbagi kedalam beberapa tahapan yaitu : a) Desk Study yang bertujuan untuk mendapatkan informasi mengenai lokasi penelitian terutama terkait dengan keberadaan Tyto alba yang menjadi objek penelitian melalui penelusuran literature; b). survey tahap 1 yang bertujuan untuk mengetahui keberadaan Tyto alba dan menentukan wilayah penelitian serta mendeskripsikannya secara umum daerah yang memungkinkan menjadi potensi sebagai tempat bersarang atau sarang aktif; c). survey tahap 2 yang bertujuan untuk dan Khalil, 2016).

mengidentifikasi tempat yang memungkinkan sebagau Pootensial Nest Site (PNS) dan Active Roost Site (ARS) yang dilakukan pada senja hari antara pukul 17.30 WIB-01.00 WIB.; d). Survey tahap 3 yang bertujuan untuk mengkonfirmasi Occupied Breeding Site (OBS) sebagai tempat perkembang biakkan baik yang sudah terjadi maupun sudah terjadi pada nest site tersebut. Metode yang digunakan adalah Look see menurut Bibby et al (1992) yaitu dengan melihat keberadaan sepasang Tyto alba dewasa, Moulted feather dan Pellets.

Pengamatan populasi Tyto alba dilakukan dengan mengacu kepada Prawiradilaga dkk (2003) dengan beberapa modifikasi. Modifikasi yang dimaksud adalah mendatangi secara langsung ke sarang aktif (berdasarkan survey sebelumnya) dan menghitung jumlah individu yang terbang dari sarang pada sore hari serta dengan melihat kedalam kandang pada siang harinya.

\section{HASIL DAN PEMBAHASAN}

A. Keberadaan Tyto alba dan Rumah Burung Hantu di Perkebunan Kelapa Sawit Kabupaten Kuantan Singingi

Berdasarkan Desk Study yang dilakukan, tidak semua perkebunan kelapa sawit di Kabupaten Kuantan Singingi yang menggunakan Tyto alba sebagai pengendali hama tikusnya. Teknologi Pengendalian hama tikus dengan Tyto alba bau dipergunakan sebatas pada perkebunan kelapa sawit swasta salah satunya adalah PT. Tri Bakti Sarimas.

Pada areal perkebunan kelapa sawit PT. Tri Bakti Sarimas, semua estatenya telah menggunakan Tyto alba sebagai pengendali hama tikus sejak tahun 2012. Luasan perkebunan kelapa sawit di PT. Tri Bkti Sarimas lebih Kurang 11.000an ha dan terbagi kedalam 5 estate. Hasil akhir dari tahapan survei lokasi perkebunan kelapa sawit yang menggunakan Tyto alba sebagai pengendali hama tikus dapat dilihat pada Tabel 1.

Tabel 1. Hasil survey lapangan penggunaan Tyto alba PT. TBS Kuantan Singingi.

\begin{tabular}{|c|c|c|c|c|}
\hline \multirow[t]{2}{*}{ Estate } & Keberadaan & \multicolumn{3}{|c|}{$\begin{array}{l}\text { Perkembang } \\
\text { biakan }\end{array}$} \\
\hline & \multirow[b]{3}{*}{$\begin{array}{l}\sqrt{ } \\
\sqrt{ } \\
\sqrt{ }\end{array}$} & $\mathbf{T}$ & $\mathbf{C}$ & $\mathbf{A}$ \\
\hline $\begin{array}{l}\text { Sei Jernih } \\
\text { Sei } \\
\text { Bingkuang }\end{array}$ & & $\begin{array}{l}- \\
-\end{array}$ & $\begin{array}{l}\sqrt{ } \\
\sqrt{ }\end{array}$ & $\sqrt{ }$ \\
\hline $\begin{array}{l}\text { Bukit } \\
\text { Payung } \\
\text { Sei Kunyit }\end{array}$ & & $\sqrt{ }$ & $\sqrt{ }$ & $\sqrt{ }$ \\
\hline
\end{tabular}




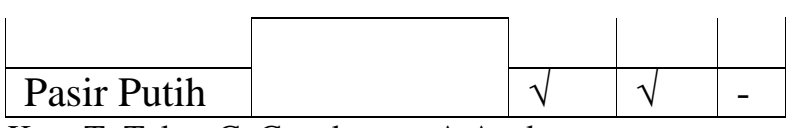

Ket : T: Telur; C: Cangkang; A Anakan

Berdasarkan Tabel 1. Terlihat pada semua estate di PT. Tri Bakti Sarimas teramati keberadaan Tyto alba. Akan tetapi hanya pada estate Bukit Payung teramati secara lengkap perkembang biakan Tyto alba (telur, cangkang dan anakan). Menurut MackKinnon dkk (2010) menyatakan bahwa Tyto alba merupakan jenis karnivora yang cukup mudah untuk berkembang biak dan tersebar luas pada dataran rendah dan dataran tinggi.

Tyto alba memiliki potensi yang sangat besar untuk mengurangi jumlah hama rodensia di perkebunan anggur dengan pembuatan kotak sarang (Wendt \& Johnson, 2017).

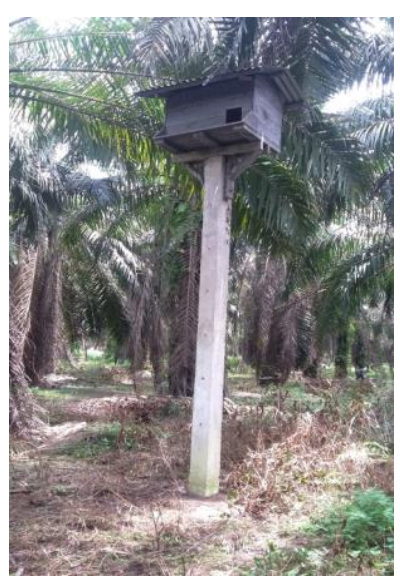

Gambar 1. Rumah Burung Hantu di PT. Tri Bakti Sarimas.

Keberadaan Tyto alba ini akan semakin mudah perkembangannya jika tersedia tempat berbiaknya karena jenis ini adalah jenis yang tidak bisa untuk membuat sarang (Tempe, 2018)

Pada Gambar 1. Tinggi Nest Box Tyto alba di PT. TBS ini adalah setinggi $4 \mathrm{~m}$ dari permukaan tanah. Hal ini bertujuan untuk menghindari serangan dari hewan pemangsa telur dan anakannya.

Pada perkebunan kelapa sawit di PT. Tribakti Sarimas pada tahun 2012 dilaksanakan program strategi pengendalian hama tikus dengan menggunakan Tyto alba sebagai musuh alami. Berdasarkan hasil pengamatan yang diperoleh di lapangan program pengendalian ini memberikan perubahan yang cukup pesat terutama dalam pengendalian hama tikus ini. Sarang aktif yang ada di areal perkebunan PT. Tri Bakti Sarimas ini cukup banyak. Hal ini terlihat pada tabel 1 yang menunjukan secara keseluruhan sarang burung hantu ini suah dimanfaatkan oleh burung hantunya. Berikut ini adalah tabel yang menunjukan persentase sarang yang dihuni oleh Tyto alba dengan petunjuk berupa terlihat secara langsung, keberadaan telur dan anakan serta bulu di dalam atau sekitar kandang.

\section{B. Populasi Tyto alba pada perkebunan kelapa sawit PT. Tri Bakti Sarimas}

Berdasarkan Tabel 1. Keberadaan Tyto alba di perkebunan kelapa sawit PT. Tri Bakti Sarimas juga dapat diketahui distribusinya yakni Sebanyak 100 buah rumah burung hantu yang disurvey pada masing masing estate di PT. Tri Bakti Sarimas di jumpai sebanyak 171 ekor Tyto alba.

Tabel 2. Jumlah Sampel rumah Tyto alba dan Jumlah Populasi yang Teramati

\begin{tabular}{|l|l|l|}
\hline Estate & $\begin{array}{l}\text { Jumlah } \\
\text { Sampel } \\
\text { rumah } \\
\text { Burung } \\
\text { Hantu }\end{array}$ & $\begin{array}{l}\text { Jumlah } \\
\text { Total } \\
\text { individu }\end{array}$ \\
\hline Sei Jernih & 20 & 41 \\
\hline $\begin{array}{l}\text { Sei } \\
\text { Bingkuang }\end{array}$ & 20 & 38 \\
\hline Bukit Payung & 20 & 46 \\
\hline $\begin{array}{l}\text { Sungai } \\
\text { Kunyit } \\
\text { Pasir Putih }\end{array}$ & 20 & 28 \\
\hline TOTAL & $\mathbf{1 0 0}$ & 18 \\
\hline
\end{tabular}


Hasil penelitian yang sama juga dijumpai oleh Daniel Harjanto, Ignatius Pramana Yuda( 2009) yang menyatakan bahwa ada nestbox yang dimanfaatkan oleh Tyto alba pada areal persawahan di daerah Moyudan Yogyakarta.

Selain pengamatn pada kandang, hasil survey lapangan dengan penagmatan pada waktu senja hari juga teramati aktivitas Tyto alba pada yang akan berburu keluar dari sarang. Tingkah laku seperti ini juga di temukan oleh Hadi, (2008) dalam penelitiannya tentang Pola Aktivitas Harian

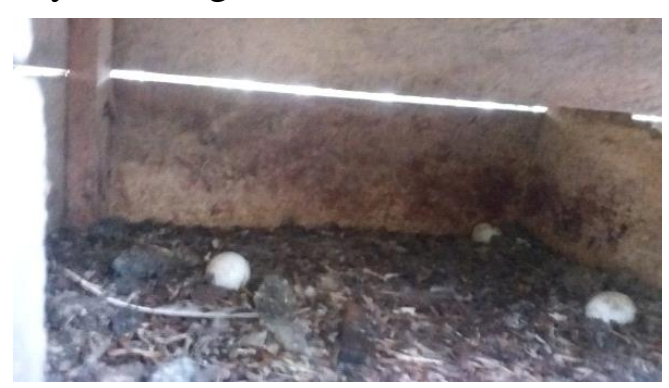

(a)
Pasangan Tyto alba di Sarang Kampus Psikologi Universitas Diponegoro Tembalang Semarang.

\section{Perkembangbikan Tyto alba pada perkebunan kelapa sawit PT. Tri Bakti Sarimas}

Pada beberapa rumah burung hantu di perkebunan kelapa sawit di PT Tribakti Sarimas dijumpai sejumlah sarang yang didalamnya terdapat sejumlah telur, anakan dan cangkang bekas telur yang telah ditetaskan.

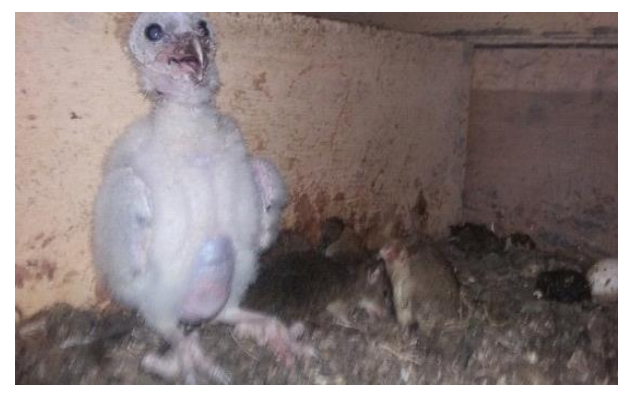

(b)

Gambar 2. (a).Telur yang gagal menetas di Nest Box di perkebunan Sei. Tiu PT. Tribakti Sarimas, (b). Anakan Tyto alba beserta Tikus mangsanya.

Terdapat beberapa rumah burung hantu di perkebunan kelapa sawit PT. Tri Bakti Sarimas teramati adanya bebeapa telur yang tidak ditetaskan. Hal ini menunjukan bahwasanya kandang kandang tersebut sebenarnya telah dimanfaatkan oleh Tyto alba sebagai tempat perkembang biakan. Tidak ditetaskannya telur tersebut bisa saja disebabkan oleh adanya akumulasi pestisida di lahan atau tanaman perkebunan sawit yang dikonsumsi oleh tikus dan berpengaruh pada telur Tyto alba yang menkonsumsinya. Menurut (Salim et al., 2015).

\section{Jumlah Mangsa Tyto alba yang dibawa kesarang}

Untuk memudahkan pengamatan populasi tikus yang dibawa kesarang oleh Tyto alba untuk pembesaran anaknya dilakukan pemasangan satu buah kamera trap di rumah burung hantu. Lokasi rumah burung hantu yang dilakukan pemasangan kamera trap adalah pada estate Bukit
Payung. Pada rumah burung hantu tersebut terdapat satu ekor anakan yang baru berumur lebih kurang 1 minggu. Selain itu juga terdapat pecahan cangkang telur serta dua buah telur yang gagal menetas. Total populasi tikus yang dibawah kesarang oleh indukan tyto alba adalah sekitar 111 ekor. Untuk melihat jumlah populasi tikus yang dibawah induk kesarang dapat dilihat pada Tabel 3.

Total jumlah tikus yang dibawa ke kandang yang teramati menggunakan kamera trap adalah sebanyak 111 ekor. Pada saat pengecekan kekandang teramati beberapa tikus mati yang masih segar di dalam kandang, selain itu juga masih dijumpai beberapa pellet segar di kandang tersebut. Daniel Harjanto, Ignatius Pramana Yuda, (2009) dalam penelitiannya juga menjumpai mangsa Tyto alba ini lebih dominan adalah tikus (Rattus argintiventer) yang dibuktikan dengan dijumpainya rangka/tengkoraknya dalam pellet Tyto alba. 
Tabel 3. Populasi Tyto alba di erkebunan kelapa sawit PT. Tri Bakti Sarimas

\begin{tabular}{|c|c|c|c|}
\hline No. & Minggu Ke & Jumlah tikus (Ekor) & Ket \\
\hline 1 & 1 & - & $\begin{array}{ll}\text { Pemasangan } & \text { Kamera } \\
\text { Trap } & \end{array}$ \\
\hline 2 & 2 & 12 & $\begin{array}{l}\text { Terdapat } 1 \text { ekor } \\
\text { individu tikus mati di } \\
\text { dalam sarang }\end{array}$ \\
\hline 3 & 3 & 19 & $\begin{array}{l}\text { Terdapat } 4 \text { ekor } \\
\text { individu tikus mati di } \\
\text { dalam sarang }\end{array}$ \\
\hline 4 & 4 & 15 & - \\
\hline 5 & 5 & 20 & $\begin{array}{l}\text { Terdapat } 3 \text { ekor } \\
\text { individu tikus mati di } \\
\text { dalam sarang }\end{array}$ \\
\hline 6 & 6 & 24 & - \\
\hline 7 & 7 & 21 & (Terdapat 2 Pellet segar) \\
\hline
\end{tabular}

\section{SIMPULAN}

Berdasarkan hasil penelitian tentang pemanfaatan Tyto alba dalam pengendalian tikus di Kuantan Singingi dapat disimpulkan bahwa di Kabupaten Kuantan Singingi penggunaan Tyto alba dalam pengendalian tikus hanya sebatas perkebunan besar swatsa. Salah satunya adalah PT. Tri Bakti Sarimas

\section{UCAPAN TERIMA KASIH}

Ucapan terima kasih kepada Direktorat Penelitian dan Pengabdian Kepada Masyarakat Kementerian Riset dan dengan luasan 11000an Ha yang terbagi kedalam 5 estate secara keseluruhan telah menggunakan Tyto alba dalam pengendalian hama tikus. Keberadaan Tyto alba pada ke 5 estate ini dijumpai dengan tanda adanya telur, anakan dan cangkang telurnya

\section{DAFTAR PUSTAKA}

Annonymous. (2016). No Title. Jakarta: Direktorat Jendral Perkebunan. Retrieved from http://ditjenbun.pertanian.go.id

Daniel Harjanto, Ignatius Pramana Yuda, A. W. N. J. (2009). Penggunaan Serak Jawa (Tyto alba) sebagai Pengendali Hama Tikus pada Persawahan Daerah

Pendidikan Tinggi yang telah mendanai kegiatan penelitian pada scheme PDP pendanaan tahun 2018.
Istimewa Yogyakarta, 1-16.

Dhamayanti, A. (2009). Kajian sosial ekonomi.pdf. In Seminar Nasional Perlindungan Tanaman (pp. 439-445). Bogor: Pusat Kajia Pengendalian Hama Terpadu Departemen Proteksi Tanaman Fakultas Pertanian Institut Pertanian Bogor. Retrieved from 
http://repository.ipb.ac.id/handle/12345 6789/54330

Hadi, M. (2008). Pola Aktivitas HarianPasangan Burung Serak Jawa ( Tyto alba ) di Sarang Kampus Psikologi Universitas Diponegoro Tembalang Semarang. BIOMA, 6(2).

Huffeldt, N. P., Aggerholm, I. N., Brandtberg, N. H., Jørgensen, J. H., Dichmann, K., \& Sunde, P. (2012). Compounding effects on nest-site dispersal of Barn Owls Tyto alba Compounding effects on nest-site dispersal of Barn Owls Tyto alba. Bird Study, 3657, 175-181. https://doi.org/10.1080/00063657.2011. 652592

Motro, Y. (2011). Economic evaluation of biological rodent control using barn owls Tyto alba in alfalfa. In 8th European Vertebrate Pest Management Confrence (pp. 79-80). https://doi.org/10.5073/jka.2011.432.04 0

Newton, I., Wyllie, I., \& Freestone, P. (1990). Rodenticides in British Barn O w $1 \mathrm{~s}, 68,101-117$.

Rajagukguk, B. H. (2014). Jurnal Saintech Vol. 06 - No.04-Desember 2014. Jurnal Saintech Vol. 06 - No.04-Desember 2014, 06(04), 1-7.

Salim, H., Hafidzi, M. N., Hamid, N. H., Agricultural, F., Sdn, S., \& Omar, D. (2015). The Effects of Rodenticide Residues Deposited in Eggs of Tyto alba to Eggshell Thickness The Effects of Rodenticide Residues Deposited in Eggs of Tyto alba to Eggshell Thickness, (April). https://doi.org/10.17576/jsm-20154404-10

Seprido. (2018). $\quad$ MODEL
AGROEKOSISTEM. In Prosiding Seminar Nasional Penelitian dan Pengabdian (pp. 1-5).

Shakir, S. H., Osborne-lee, I. W., Paolo, G., Misso, R., \& Khalil, M. T. (2016). Ecological Agro-ecosystem Sustainable Development in Relationship to Other Sectors in the Economic System, and Human Ecological Footprint and Imprint. Agriculture and Agricultural Science Procedia, 8, 17-30. https://doi.org/10.1016/j.aaspro.2016.02 .004

Shawyer, C. R. (2011). Barn Owl Tyto alba Survey Methodology and Techniques for use in Ecological Assessment: Developing Best Practice in Survey and Reporting. Winchester: IEEM.

Singh, Minerva and Bhagwat, S. A. (2013). Tropical agricultural production, conservation and carbon sequesteration conflicts : oil palm expansion in Book Chapter.

https://doi.org/http://dx.doi.org/10.5772 152420

Tempe, R. J. w. C. M. dan J. R. B. (2018). Assessing patterns of Barn Owl ( Tyto alba ) occupancy from call broadcast surveys Assessing patterns of barn owl Tyto alba occupancy from call broadcast surveys. BioOne Research Evolved, (December). https://doi.org/https://doi.org/10.2981/w lb.00411

Wendt, C. A., \& Johnson, M. D. (2017). Agriculture , Ecosystems and Environment Multi-scale analysis of barn owl nest box selection on Napa Valley vineyards. Agriculture, Ecosystems and Environment, 247(November 2016), 75-83. https://doi.org/10.1016/j.agee.2017.06.0 23 